\title{
Potential of Bryophyllum pinnatum as a Detrusor Relaxant: An in Vitro Exploratory Study
}

\author{
INAUGURAL-DISSERTATION \\ zur Erlangung der Doktorwürde der Humanmedizin \\ der Medizinischen Fakultät \\ der Universität Zürich
}

vorgelegt von

Simon Ronnie Bachmann

Genehmigt auf Antrag von Prof. Dr. med. Daniel Fink 